\title{
SELEKSI VARIETAS PADI HASIL PERSILANGAN MELALUI KEGIATAN PARTICIPATORY PLANT BREEDING (PPB)
}

\author{
Puspita Deswina*, Eko Binnaryo Mei Adi, Enung Sri Mulyaningsih \\ Pusat Penelitian Bioteknologi, LIPI \\ Jl. Raya Bogor Km 46 Cibinong Science Center, 16911 \\ Telpon 021-8754587, Fax. 021-8754588 \\ *pdeswina@gmail.com
}

\begin{abstract}
Improving the quality of rice crops is the first priority to reach the high productivity and food security in Indonesia. Food needs and nutritional adequacy of the community can be met if the quality of rice increases, so the goal of food self-sufficiency can be realized. The policy of importing rice should immediately end by providing premium-quality rice so that major food needs can be provided. Rice production in Indonesia should be continuously improved to balance with the increasing of growth population every year. Various efforts have been made such as improving the quality of rice to provide better results. The research objectives were selection and evaluation of rice varieties through participatory plant breeding with rice field farmer respondents. Rice farmers from Cibinong, Bogor and surrounding areas were asked to provide an assessment of the morphological characteristics of cross rice crops. The research objectives were selection and evaluation of rice varieties through participatory plant breeding with rice field farmer respondents. Rice farmers from Cibinong, Bogor and surrounding areas were asked to provide an assessment of the morphological characteristics of cross rice crops. The highest assessment result was P3 strain (402) selected by 15 farmers, then P1 (275) selected by 11 farmers. The most preferred varieties of rice are Limboto and IR 64.
\end{abstract}

Key words: participatory plant breeding, agronomic characteristic, rice selection

\section{PENDAHULUAN}

Kebutuhan beras nasional menjadi isu utama dalam setiap kebijakan pemerintah dalam mengambil keputusan dalam meningkatkan kesejahteraan masyarakat. Kebijakan swasembada pangan merupakan target pemerintah, terutama dalam memenuhi kebutuhan pangan utama. Berdasarkan data statistik diketahui bahwa produksi padi nasional pada 2014 sekitar 69.9 juta ton dengan produktivitas 51,49 ton/ha (BPS, 2015). Pembangunan ketahanan pangan sangat penting bagi Indonesia yang mempunyai jumlah penduduk sangat besar, sehingga kebutuhan pangan nasional akan terus bertambah dari tahun ke tahun sebagai akibat jumlah penduduk yang terus meningkat. Jumlah penduduk tahun 2010 sebesar 237,5 juta jiwa, dimana 53,45\% berada di Pulau Jawa dengan laju pertumbuhan sebesar 1,49\% (BPS, 2011). Diperkirakan pada tahun 2020, penduduk Indonesia berjumlah 250 juta jiwa. Selain itu Indonesia merupakan negara dengan tingkat kebutuhan beras tertinggi di dunia yaitu sebesar $139 \mathrm{~kg}$ per orang/tahun. Menurut laporan FAO (2009) rata-rata konsumsi beras dunia hanya $54 \mathrm{~kg}$ per orang/tahun. Selain kebutuhan beras yang semakin terus meningkat, terdapat persoalan alih fungsi lahan yang turut 
berperan dalam penurunan produksi padi nasional. Data BPS 2004 menunjukkan bahwa besaran alih fungsi lahan pertanian sawah ke non sawah sebesar 187.720 ha/tahun dan alih fungsi lahan kering pertanian ke non pertanian 9.152 ha/tahun. Sembiring (2015) mengatakan, bahwa kendala dalam peningkatan produksi semakin kompleks karena berbagai perubahan dan perkembangan lingkungan strategis diluar sektor pertanian berpengaruh dalam peningkatan produksi tanaman. Ancaman terganggunya ketahanan pangan karena berkurangnya produktivitas, sudah di depan mata, oleh karena itu program nasional peningkatan kuantitas dan kualitas padi menjadi sasaran utama dalam menyusun program pembangunan nasional. Tercapainya ketahanan pangan merupakan kondisi terjaminnya akses pangan yang cukup gizi bagi setiap orang pada setiap waktu, aman bagi kesehatan serta sesuai dengan nilai social, agama dan kepercayaan agar dapat hidup sehat dan produktif (Kementan, 2013).

Orientasi petani dan perkembangan teknologi yang digunakan petani dalam budidaya padi yang beragam telah menimbulkan persepsi yang berbeda-beda terhadap benih bermutu, selain itu keragaman sistim perbenihan menjadi sumber penyediaan benih bagi petani. Keragaman potensi genetik padi yang tersedia untuk meningkatkan produktivitas di Indonesia masih cukup luas. Seperti padi tipe baru (PTB) yang memiliki potensi untuk meningkatkan produktivitas dengan meningkatkan jumlah malai/gabah dan jumlah anakan produktif per rumpun (Kementan, 2013).

Perakitan galur tanaman padi unggul dapat mendukung ketahanan pangan nasional dengan beragam cara seperti persilangan dan pemuliaan yang dipadukan dengan seleksi menggunakan marka molekuler, manipulasi sel somatik, rekayasa kultur in vitro dan rekayasa genetik. Seluruh teknik tersebut telah diaplikasikan pada perakitan dan seleksi galur unggul padi, dan tanaman pangan lainnya (Khush, 2000). Teknologi pertanian harus mampu menjawab berbagai keterbatasan terhadap ketersediaan sumberdaya alam di tengah berkembangnya kebutuhan manusia yang seolah-olah tanpa batas.

Salah satu strategi untuk meningkatkan produktivitas, kualitas, serta daya saing komoditas tanaman melalui pelepasan kultivar baru yang memiliki keunggulan karakter sesuai dengan permasalahan yang terdapat di lapangan. Perakitan verietas padi dengan melibatkan petani sebagi pengguna dimungkinkan dengan melakukan pendekatan pemuliaan partisipatif (Participatory Plant Breeding/ PPB), sehingga diharapkan keterlibatan tersebut dapat mempercepat proses adopsi varietas baru yang dihasilkan. Di samping itu kultivar unggul yang diperoleh adalah yang sesuai dengan keinginan petani dan adaptif terhadap lingkungan yang spesifik. Pelaksanaan pemuliaan partisipatif 
pada daerah lahan sawah didesa Cibinong telah dilaksanakan dengan menggunakan galur-galur padi generasi lanjut (F6) dan menghasilkan beberapa galur harapan yang disukai petani secara morfologi, Petani umumnya lebih menyukai jenis tanaman yang memiliki nilai aksesptibilitas yang tinggi serta faktor rasa dari beras yang dihasilkan, meskipun nilai produktivitasnya rendah (Seno et al., 2011). Untuk meningkatkan produksi dan memenuhi kebutuhan pangan, maka pelepasan kultivar baru didasarkan pada kesesuaian agroekologi setempat dan lebih bersifat regional (Zuraida dan Sumarno, 2003).

\section{METODOLOGI}

\section{Lokasi Penelitian}

Penelitian dilaksanakan di areal pertanaman sawah sekitar Puslit Bioteknologi LIPI, Cibinong Science Center, Kab Bogor, pada bulan Oktober 2016. Jumlah galur yang ditanam adalah 60 galur padi gogo hasil persilangan yang memiliki sifat toleran alumunium (Tabel 1). Tanaman disemai pada tanggal 25 April 2016 dan ditanam tanggal 18 Mei 2016. Pada saat tanaman sudah memasuki usia panen, yang ditandai dengan kondisi tanaman sudah 60\% memasuki masa masak fisiologis dilakukan kegiatan Participatory Plant Breeding (PBB) dengan mengundang petani yang berada di sekitar daerah Cibinong, Kabupaten Bogor untuk membuat penilaian terhadap padi hasil persilangan meliputi karakter-karakter agronomis yang mereka nilai baik sesuai dengan kesukaan umum petani di wilayah tersebut. Jumlah responden petani yang diundang 25 orang, dengan latar belakang usia, jenis kelamin dan pendidikan yang berbeda-beda. Penanaman galur-galur ini menggunakan 5 varietas pembanding (Inpago LIPI Go 2, Limboto, Danau Gaung, Situpatenggang, IR 64). Jarak tanam $0,25 \times 0,25 \mathrm{~m}$ dengan ukuran petakan $2 \times$ $2 \mathrm{~m}$, dan jarak antar petak $50 \mathrm{~cm}$. Pemupukan, diberikan sebanyak dua kali yaitu pada umur 14 hst (hari setelah tanam), dengan dosis TSP 100 $\mathrm{kg} / \mathrm{ha}$, KCL $75 \mathrm{~kg} / \mathrm{ha}$, Urea $100 \mathrm{~kg} / \mathrm{ha}$ dan pemupukan kedua diberikan pada usia 50 hst, atau menjelang berbunga dengan dosis $100 \mathrm{~kg}$ Urea/ha.

\section{Metode Analisis Data}

Metode penelitian melalui wawancara dan pengisian kuisioner oleh responden petani, untuk mengetahui jenis padi silangan yang lebih disukai petani di daerah Cibinong Kabupaten Bogor. Teknik pengumpulan data sebagai sumber informasi melalui data primer dan data sekunder dari Badan Meteorologi, Klimatologi dan Geofisika (BMKG), Kabupaten Bogor. Responden petani diminta mengisi kuisioner (Lampiran 1) yang telah disiapkan sesuai dengan pendapat dan penilaian mereka terhadap tanaman padi hasil persilangan generasi keenam (F6). 
Deswina dkk, SELEKSI VARIETAS PADI...

Tabel 1: Daftar tanaman padi gogo hasil persilangan koleksi Puslit Bioteknologi LIPI

\begin{tabular}{|c|c|c|c|}
\hline No & No persilangan & $\begin{array}{l}\text { No Galur } \\
\text { tanaman }\end{array}$ & Asal persilangan \\
\hline 1 & P1 & 2 & TB368B-TB-25-MR-2 X B11178G-TB-29 \\
\hline 2 & P1 & 45 & TB368B-TB-25-MR-2 X B11178G-TB-29 \\
\hline 3 & P1 & 62 & TB368B-TB-25-MR-2 X B11178G-TB-29 \\
\hline 4 & $\mathrm{P} 1$ & 72 & TB368B-TB-25-MR-2 X B11178G-TB-29 \\
\hline 5 & P1 & 75 & TB368B-TB-25-MR-2 X B11178G-TB-29 \\
\hline 6 & $\mathrm{P} 1$ & 223 & TB368B-TB-25-MR-2 X B11178G-TB-29 \\
\hline 7 & P1 & 233 & TB368B-TB-25-MR-2 X B11178G-TB-29 \\
\hline 8 & P1 & 235 & TB368B-TB-25-MR-2 X B11178G-TB-29 \\
\hline 9 & P1 & 239 & TB368B-TB-25-MR-2 X B11178G-TB-29 \\
\hline 10 & $\mathrm{P} 1$ & 247 & TB368B-TB-25-MR-2 X B11178G-TB-29 \\
\hline 11 & P1 & 248 & TB368B-TB-25-MR-2 X B11178G-TB-29 \\
\hline 12 & P1 & 251 & TB368B-TB-25-MR-2 X B11178G-TB-29 \\
\hline 13 & P1 & 259 & TB368B-TB-25-MR-2 X B11178G-TB-29 \\
\hline 14 & $\mathrm{P} 1$ & 261 & TB368B-TB-25-MR-2 X B11178G-TB-29 \\
\hline 15 & P1 & 264 & TB368B-TB-25-MR-2 X B11178G-TB-29 \\
\hline 16 & P1 & 269 & TB368B-TB-25-MR-2 X B11178G-TB-29 \\
\hline 17 & P1 & 275 & TB368B-TB-25-MR-2 X B11178G-TB-29 \\
\hline 18 & $\mathrm{P} 1$ & 289 & TB368B-TB-25-MR-2 X B11178G-TB-29 \\
\hline 19 & $\mathrm{P} 1$ & 443 & TB368B-TB-25-MR-2 X B11178G-TB-29 \\
\hline 20 & $\mathrm{P} 1$ & 452 & TB368B-TB-25-MR-2 X B11178G-TB-29 \\
\hline 21 & $\mathrm{P} 1$ & 453 & TB368B-TB-25-MR-2 X B11178G-TB-29 \\
\hline 22 & $\mathrm{P} 1$ & 465 & TB368B-TB-25-MR-2 X B11178G-TB-29 \\
\hline 23 & $\mathrm{P} 1$ & 468 & TB368B-TB-25-MR-2 X B11178G-TB-29 \\
\hline 24 & $\mathrm{P} 2$ & $83 \mathrm{~B}$ & Situ Patenggang X B11930F-TB-2 \\
\hline 25 & $\mathrm{P} 2$ & 220 & Situ Patenggang X B11930F-TB-2 \\
\hline 26 & $\mathrm{P} 2$ & 305 & Situ Patenggang X B11930F-TB-2 \\
\hline 27 & $\mathrm{P} 2$ & 412 & Situ Patenggang X B11930F-TB-2 \\
\hline 28 & P3 & 18 & Inpago 8 X B11930F-TB-2 \\
\hline 29 & P3 & 27 & Inpago 8 X B11930F-TB-2 \\
\hline 30 & P3 & 89 & Inpago 8 X B11930F-TB-2 \\
\hline 31 & $\mathrm{P} 3$ & 93 & Inpago 8 X B11930F-TB-2 \\
\hline 32 & $\mathrm{P} 3$ & 103 & Inpago 8 X B11930F-TB-2 \\
\hline 33 & P3 & 178 & Inpago 8 X B11930F-TB-2 \\
\hline 34 & P3 & 182 & Inpago 8 X B11930F-TB-2 \\
\hline 35 & P3 & 310 & Inpago 8 X B11930F-TB-2 \\
\hline 36 & P3 & 322 & Inpago 8 X B11930F-TB-2 \\
\hline 37 & $\mathrm{P} 3$ & 402 & Inpago 8 X B11930F-TB-2 \\
\hline 38 & $\mathrm{P} 3$ & 404 & Inpago 8 X B11930F-TB-2 \\
\hline 39 & $\mathrm{P} 4$ & 109 & B11492F-TB-12 X B11178G-TB-29 \\
\hline 40 & P4 & $117 \mathrm{~A}$ & B11492F-TB-12 X B11178G-TB-29 \\
\hline 41 & P4 & 117B & B11492F-TB-12 X B11178G-TB-29 \\
\hline
\end{tabular}


Deswina dkk, SELEKSI VARIETAS PADI...

\begin{tabular}{llll}
42 & P4 & 123 & B11492F-TB-12 X B11178G-TB-29 \\
43 & P4 & $154 \mathrm{~A}$ & B11492F-TB-12 X B11178G-TB-29 \\
44 & P4 & 337 & B11492F-TB-12 X B11178G-TB-29 \\
45 & P4 & 350 & B11492F-TB-12 X B11178G-TB-29 \\
46 & P4 & 356 & B11492F-TB-12 X B11178G-TB-29 \\
47 & P4 & $417 \mathrm{~A}$ & B11492F-TB-12 X B11178G-TB-29 \\
48 & P4 & $417 B$ & B11492F-TB-12 X B11178G-TB-29 \\
49 & P4 & 428 & B11492F-TB-12 X B11178G-TB-29 \\
50 & P4 & 430 & B11492F-TB-12 X B11178G-TB-29 \\
51 & P4 & 475 & B11492F-TB-12 X B11178G-TB-29 \\
52 & P5 & 39 & Danau Gaung X Situ Patenggang \\
53 & P5 & 195 & Danau Gaung X Situ Patenggang \\
54 & P5 & 201 & Danau Gaung X Situ Patenggang \\
55 & P5 & 206 & Danau Gaung X Situ Patenggang \\
56 & P5 & 367 & Danau Gaung X Situ Patenggang \\
57 & P5 & 368 & Danau Gaung X Situ Patenggang \\
58 & P5 & 370 & Danau Gaung X Situ Patenggang \\
59 & P5 & 384 & Danau Gaung X Situ Patenggang \\
60 & P6 & 458 & B11908F-TB-2 X Situ Patenggang \\
\hline
\end{tabular}

Hasil penilaian petani tersebut dianalisis dan diolah menggunakan program Microsoft Excell 10. Pengambilan atau pemilihan responden dilakukan secara purposive random sampling (Brockett \& Levine 1984) berdasarkan beberapa pertimbangan populasi petani di daerah sampling yang tersebar cukup luas, dan membutuhkan biaya yang cukup mahal untuk memperoleh data sesuai dengan target informasi yang diperlukan. Oleh karena itu responden yang dipilih dianggap sudah mewakili daerah yang diteliti sesuai dengan jumlah kelompok tani yang tersedia. Data sekunder dijadikan bahan penunjang dalam pembahasan hasil penelitian. Data dari hasil kuisioner disusun dan ditabulasi berdasarkan kriteria-kriteria yang diperlukan. Seluruh data kemudian disajikan dalam bentuk Tabel hasil penelitian terkait dengan sifat-sifat agronomik yang diamati. Analisis data dibuat dalam bentuk deskriptif berdasarkan pada tingkat pengetahuan dan pengalaman responden petani. Metode pemilihan dan menentukan jumlah responden berdasarkan purposive random sampling menggunakan rumus sebagai berikut:

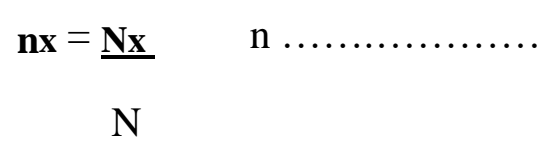

Dimana: $\mathrm{nx}=$ jumlah responden (sampel)

$$
\begin{aligned}
& \mathrm{N}=\text { jumlah seluruh populasi } \\
& \mathrm{Nx}=\text { jumlah populasi setiap strata } \\
& \mathrm{n}=\text { ukuran responden secara }
\end{aligned}
$$
keseluruhan

Hasil wawancara dan pengisian kuisioner disajikan dalam bentuk Tabel, dengan kriteria pengamatan terhadap tinggi tanaman (TT), 
jumlah anakan produktif (JAP), jumlah anakan total (JAT), jumlah gabah total (GT), persentase gabah hampa (\%GH), panjang malai (PM), umur berbunga (UB), umur tanaman (UP) dan jumlah produksi tanaman (P). Sebagai varietas pembanding digunakan lima jenis tanaman padi gogo lokal Situ patenggang, Limboto, LIPI Go 2, Danau Raung dan satu padi sawah IR 64.

\section{HASIL DAN PEMBAHASAN}

\section{Pengaruh faktor lingkungan terhadap produksi tanaman}

Penanaman galur padi gogo hasil persilangan dilakukan pada bulan Mei 2016 saat akhir musim hujan, tetapi pada saat tanam terjadi anomali cuaca dimana curah hujan terjadi pada musim kemarau dengan intensitas tetap tinggi (kamarau basah). Berdasarkan data BMKG Kabupaten Bogor (BPS, 2017) intensitas curah hujan di Kabupaten Bogor pada tahun 2016 termasuk kategori tertinggi, terjadi di bulan
Januari $(675 \mathrm{~mm})$ dan terendah pada bulan Desember (147 mm), dengan jumlah hari hujan terbanyak pada bulan Februari sebanyak 21 hari hujan. Selama berjalannya penelitian antara bulan Mei hingga September, terdapat jumlah hari hujan 57 hari hujan terdapat pada setiap bulan dengan intensitas $1621 \mathrm{~mm}$. Tingginya curah hujan selama penelitian berpengaruh terhadap intesitas cahaya matahari dengan intensitas tertinggi terdapat pada bulan Juli dengan 59\% dan terendah pada bulan Mei dan September (47\%). Selama penelitian intensitas cahaya matahari rata-rata 52\% (Tabel 2). Dari data yang tersaji, dapat disimpulkan bahwa selama penelitian berlangsung terjadi kondisi cuaca yang tidak biasanya, sehingga memberikan pengaruh terhadap karakter morfologi tanaman padi gogo hasil persilangan yang sedang diamati.

Tabel 2. Data iklim untuk suhu udara, kelembaban dan intensitas cahaya di Kabupaten Bogor tahun 2016

\begin{tabular}{lccccccccc}
\hline \multicolumn{1}{c}{ Bulan } & \multicolumn{3}{c}{ Suhu rata-rata } & \multicolumn{3}{c}{ Kelembaban udara } & $\begin{array}{c}\text { Intensitas } \\
\text { cahaya }\end{array}$ & $\begin{array}{c}\text { jumlah } \\
\text { hari hujan }\end{array}$ & $\begin{array}{c}\text { Curah } \\
\text { hujan }\end{array}$ \\
\cline { 2 - 10 } & Min & Mak & Rerata & Min & Mak & rerata & Rerata & Cibinong & Cibinong \\
\hline Januari & 23.7 & 32.1 & 26.4 & 53 & 98 & 86 & 44 & 17 & 675 \\
Februari & 23.3 & 30.8 & 25.7 & 64 & 98 & 89 & 24 & 21 & 468 \\
Maret & 23.7 & 32.0 & 26.5 & 55 & 98 & 86 & 42 & 17 & 372 \\
April & 24.0 & 32.7 & 26.7 & 55 & 98 & 85 & 46 & 16 & 600 \\
Mei & 24.1 & 32.6 & 27.1 & 50 & 97 & 84 & 47 & 12 & 288 \\
Juni & 23.1 & 31.9 & 26.2 & 50 & 99 & 84 & 49 & 10 & 273 \\
Juli & 22.8 & 32.0 & 26.1 & 52 & 97 & 83 & 59 & 8 & 353 \\
Agustus & 22.7 & 32.2 & 26.1 & 40 & 97 & 82 & 55 & 15 & 307 \\
September & 23.2 & 31.8 & 26.2 & 53 & 97 & 83 & 47 & 12 & 401 \\
Oktober & 23.3 & 31.5 & 26.0 & 58 & 98 & 87 & 30 & 17 & 540 \\
Nopember & 23.3 & 31.5 & 26.0 & 58 & 98 & 87 & 34 & 17 & 585 \\
Desember & 23.0 & 30.9 & 26.0 & 55 & 97 & 82 & 31 & 10 & 147 \\
\hline
\end{tabular}

Sumber: BMKG (2017) 
Respon fenotip tanaman merupakan interaksi antara faktor genetik dan lingkungan yang membentuk karakter morfologi. Faktor lingkungan seperti curah hujan, temperatur udara, kelembaban, intensitas cahaya akan mempengaruhi karakter agronomis, seperti tinggi tanaman, jumlah gabah hampa dan isi permalai. Pertumbuhan optimum padi akan terjadi pada kondisi suhu minimum diatas $20^{\circ} \mathrm{C}$ dan suhu maksimum $40^{\circ} \mathrm{C}$, sedangkan suhu optimum sekitar $30^{\circ} \mathrm{C}$ (Shivani et al., 2017).

Berdasarkan data yang disajikan pada Tabel 2, diketahui bahwa rata-rata intensitas matahari sepanjang tahun selama 2016 adalah 42\%, angka ini tergolong rendah. Hal ini mempengaruhi produktivitas, terutama dalam meningkatkan jumlah gabah hampa pada seluruh genotype yang ditanam pada uji daya hasil pendahuluan (UDHP) padi hasil persilangan ini. Intensitas cahaya matahari akan mempengaruhi proses penyerbukan bunga padi, selain itu rendahnya intensitas cahaya matahari juga mempengaruhi laju pengisian asimiliat pada gabah. Hampir seluruh genotype menghasilkan gabah hampa yang tinggi antara $31.2 \%$ hingga $98.4 \%$ dan hanya satu genotype P4 117B-1 yang memiliki gabah hampa $19.6 \%$ bahkan beberapa genotype mendekati 100\% (Tabel 3). Intensitas cahaya matahari rata-rata kurang dari 50\%, akan menurunkan jumlah anakan, jumlah gabah per malai, dan produksi (mengurangi gabah yang fertile, rendahnya akumulasi bahan kering, mengurangi gabah isi dan bobot 1000 biji (Qihua et al., 2014). Anomali cuaca yang terjadi sepanjang Tahun 2016 berpengaruh terhadap kemampuan padi dalam melakukan penyerbukan, sehingga memberikan efek negatif terhadap produksi tanaman secara keseluruhan.

Varietas pembanding yang digunakan termasuk jenis padi gogo yang biasa ditumbuhkan dilahan kering seperti varietas limboto, situ patenggang dan danau gaung, tetapi jenis-jenis ini juga ditanam di lahan sawah dan berair, dengan tujuan yang sama dengan padi hasil silangan, yaitu mengetahui kemampuan adaptasi dari padi tersebut di lahan sawah. Varietas IR64 merupakan pembanding untuk jenis padi sawah, dengan produksi 2.7 ton/ha (Tabel 4), angka tertinggi dalam pengujian ini. Respon yang ditunjukkan oleh varietas-varietas pembanding beragam, terutama terhadap produksi per hektar yang diperoleh. Varietas Limboto memberikan hasil sebesar 1.7 ton/ha, diikuti Danau Gaung dan Situpatenggang (1.4 ton/ha) (Tabel 4). Produktivitas padi gogo pembanding yang digunakan pada penelitian ini jauh di bawah produksi standar di lapangan. Menurut Bakhtiar et al. (2013) produktivitas padi gogo varietas Inpago 6 sekitar 5,8 ton/ha, Limboto sekitar 2,7 - 3,6 ton/ha, Situ patenggang 2,47 - 2,88 ton/ha, sedangkan padi gogo Danau Gaung menurut Balitbang (2001) mampu menghasilkan gabah kering giling sekitar 3,4 ton/ha. Rendahnya produksi padi 
gogo di lahan percobaan bisa diakibatkan oleh kondisi lahan dan iklim yang tidak menentu sehingga pertumbuhan optimal padi gogo ini tidak dapat tercapai.

\section{Keragaan karakter agronomis tanaman}

Pada uji daya hasil pendahuluan ini, tanaman padi hasil persilangan yang digunakan adalah tanaman generasi $F_{6}$, yang ditanam pada lahan sawah irigasi. Dari Tabel 3 dapat dilihat bahwa hasil rata-rata produksi tertinggi dicapai oleh genotype P1 223 dengan hasil 3.1 ton/ha gabah kering giling dan lima genotype padi lainnya (P3 402; P1 247; P1 259; P5 39; P1 251) menunjukan produksi 2 ton/ha atau lebih. Sedangkan varietas pembanding IR 64 menghasilkan produksi paling tinggi yaitu 2.7 ton/ha. Rendahnya produksi padi hasil persilangan yang dihasilkan, karena jenis padi tersebut termasuk padi gogo yang memiliki sifat tumbuh lebih baik di tanah kebun dibandingkan lahan sawah. Tetapi dalam penelitian ini terdapat tujuan dalam untuk melakukan pemuliaan padi hasil persilangan, agar diperoleh padi amfibi yang memiliki sifat dapat ditanam di lahan sawah dan lahan kering (ladang). Tujuan menanam di lahan sawah untuk mengetahui kemampuan adaptasi dan produksi padi-padi tersebut jika ditumbuhkan di lahan sawah yang relatif lebih basah dan tergenang. Dari hasil pengamatan, ternyata produksi padi jauh lebih rendah bila dibandingkan tanaman padi tersebut ditumbuhkan pada kondisi kering atau dilahan perkebunan yang lebih sesuai untuk jenis padi gogo. Kegiatan pemuliaan dengan metode seleksi merupakan proses yang efektif untuk memperoleh sifat-sifat yang dianggap sangat penting dengan tingkat keberhasilan lebih tinggi (Sadimantara et al. 2013).

Berdasarkan karakter agronomic pada Tabel 3 , umur berbunga dan umur panen galur yang diuji pada padi hasil silangan, menunjukan umur panen dari 98 hss hingga 140 hss, umur berbunga dari 73 (P3 27) hingga 102 hss (P3 310, P4 337, P1 289 dan P1 247), hasil ini menunjukan rentang yang lebar antar galur yang di uji. Sedangkan karakter umur terpendek terdapat pada galur P4 117B yaitu 98 hss, dan terpanjang pada P1 468 yaitu 140 hss. Dilihat dari deskripsi varietas padi gogo, rentang waktu panen padi gogo pembanding berkisar antara 105-120 hss (Tabel 4). Umur pendek biasanya hasilnya rendah karena tidak mempunyai cukup waktu untuk tanaman menggunakan sinar matahari dan hara dari dalam tanah, sehingga tidak cukup waktu pertumbuhan vegetatifnya untuk hasil yang maksimum (Bakhtiar et al. 2013). Pada padi hasil silangan menunjukan daya adaptasi terhadap lingkungan, sesuai dengan tujuan utama dalam UDHP ini adalah merakit padi amfibi yang dapat ditanam pada lahan sawah dan kering.

Hasil pengamatan terhadap karakter tinggi tanaman dari galur-galur hasil persilangan pada Tabel 3, memiliki kisaran dari 73,7 cm - 166,2 
cm untuk galur P4 475-1 dan galur P5 384-1. Petani padi lebih menyukai tanaman padi yang tidak begitu tinggi dan tidak begitu pendek, karena padi yang tinggi lebih mudah rebah pada waktu memasuki masa berbuah, sebaliknya padi yang berukuran pendek lebih sulit pada waktu dipanen. Menurut Makarim dan. Suhartatik (2009) pengelompokan tanaman padi dapat dilakukan juga berdasarkan karakter batang terutama pertumbuhan batangnya. Batang yang pendek dan kaku merupakan sifat yang dikehendaki dalam pengembangan varietasvarietas unggul padi karena tahan rebah. Produktivitas tanaman padi juga ditentukan oleh batang padi yang kokoh, sehingga tanaman tidak mudah rebah dan akhirnya dapat menekan produksi (Sadimantara et al. 2013).

Jumlah anakan produktif tertinggi terdapat pada galur P5 39 (21.2), sebaliknya jumlah anakan paling sedikit adalah galur P3 310-1 (6.7). Varietas dengan jumlah anakan per rumpun yang disertai dengan jumlah gabah per malai banyak akan memungkinkan memberikan hasil lebih tinggi dibandingkan varietas dengan jumlah anakan dan jumlah gabah per malai yang lebih sedikit (Virk et al. 2003). Akan tetapi jumlah anakan yang terlalu banyak juga kurang diminati oleh petani, karena akan mengurangi jumlah gabah optimal pada rumpun yang produktif. Sedangkan untuk kriteria panjang malai sangat berhubungan dengan produksi.
Menurut Kartina et al. (2016) panjang malai merupakan karekter yang berkorelasi dengan hasil, makin panjang malai akan meningkat jumlah gabah yang terbentuk, sehingga produksi akan naik. Galur P3 404-1 memiliki panjang malai yang tertinggi dibandingkan dengan galurgalur lainnya, tetapi tidak memperlihatkan jumlah produksi yang tertinggi, diduga karena factor lingkungan seperti iklim dan tanah yang tidak optimal untuk pertumbuhan padi gogo. Selain itu tingginya persentase gabah hampa juga mempengaruhi terhadap produksi tanaman.

Untuk karakter agronomi tinggi tanaman galur- galur pembanding, LIPI Go2 merupakan tanaman yang paling tinggi $(132.1 \mathrm{~cm})$, sedangkan yang paling pendek adalah galur IR64 dengan tinggi $94.5 \mathrm{~cm}$ (Tabel 4). Kebanyakan petani tidak begitu menyukai tanaman padi yang tinggi karena mudah rebah disaat tanaman memasuki fase pembuahan. Perbedaan susunan genetik merupakan salah satu faktor penyebab keragaman penampilan tanaman dalam hal tinggi tanaman. Sesuai dengan pendapat Susilaningsih et al. (2008) bahwa perbedaan tinggi tanaman lebih ditentukan oleh faktor genetik, disamping pengaruh kondisi lingkungan tumbuh tanaman. Apabila lingkungan tumbuh sesuai bagi pertumbuhan tanaman, maka dapat meningkatkan produksi tanaman. 
Deswina dkk, SELEKSI VARIETAS PADI...

Tabel 3: Karakter Agronomik galur-galur Uji Daya Hasil Pendahuluan karakter agronomik 56 galur generasi keenam $\left(\mathrm{F}_{6}\right)$

\begin{tabular}{|c|c|c|c|c|c|c|c|c|c|}
\hline Galur & $\begin{array}{l}\mathrm{TT} \\
(\mathrm{cm})\end{array}$ & JAP & JAT & GT & $\% \mathrm{GH}$ & $\mathrm{PM}(\mathrm{cm})$ & UB (hss) & UP (hss) & $\begin{array}{c}\mathrm{P} \\
\text { (ton/ha) }\end{array}$ \\
\hline P1 223 & 121.7 & 11 & 12.3 & 196.4 & 55.1 & 27.2 & 94 & 126 & 3.1 \\
\hline P3 402 & 126.6 & 7.6 & 14.4 & 215.4 & 57 & 31.7 & 92 & 111 & 2.6 \\
\hline P1 247 & 118.3 & 16.7 & 18.7 & 192.7 & 42.7 & 29.5 & 102 & 129 & 2.4 \\
\hline P1 259 & 125.6 & 12.8 & 20.4 & 160.5 & 46.4 & 25.4 & 82 & 111 & 2.3 \\
\hline P5 39 & 91 & 21.2 & 52 & 128.2 & 44.9 & 25.4 & 88 & 119 & 2.1 \\
\hline P1 251 & 119 & 11.8 & 12.3 & 182.6 & 34.3 & 26.8 & 94 & 130 & 2 \\
\hline P3 178 & 120.4 & 8.6 & 16 & 181.5 & 75.8 & 30.9 & 86 & 111 & 1.9 \\
\hline P5 368 & 138.6 & 8.4 & 13.2 & 176.8 & 52.7 & 30.9 & 86 & 113 & 1.9 \\
\hline P1 239 & 108.5 & 16.5 & 17 & 127.3 & 60.1 & 25.5 & 94 & 133 & 1.9 \\
\hline P2 412 & 105.2 & 7.2 & 21 & 97.7 & 96.6 & 25.5 & 83 & 109 & 1.9 \\
\hline P1 452 & 119.7 & 8.7 & 12 & 240.4 & 64 & 27.7 & 88 & 123 & 1.8 \\
\hline P1 289 & 101.3 & 15 & 16.7 & 145 & 48.5 & 24.5 & 102 & 126 & 1.8 \\
\hline P1 261 & 109.3 & 16 & 23.7 & 150.8 & 38.9 & 25.9 & 93 & 130 & 1.7 \\
\hline P3 27 & 123.6 & 7.4 & 6.6 & 229.3 & 72.5 & 26.6 & 73 & 111 & 1.6 \\
\hline P1 62 & 104.7 & 9.7 & 12 & 144 & 47.2 & 25.9 & 95 & 129 & 1.6 \\
\hline P3 322 & 129.4 & 13.6 & 19.4 & 154.7 & 55.7 & 30.4 & 84 & 111 & 1.6 \\
\hline P4 430-1 & 125.8 & 10.8 & 22.8 & 217.2 & 66.9 & 25.9 & 83 & 112 & 1.5 \\
\hline P5 201-1 & 155.6 & 14 & 14.8 & 170.6 & 81.3 & 30.8 & 88 & 111 & 1.5 \\
\hline P3 18-1 & 142.8 & 7.4 & 19.4 & 172.7 & 54.6 & 28.3 & 93 & 123 & 1.4 \\
\hline P3 404-1 & 117 & 9 & 13 & 207.2 & 79.3 & 31.3 & 88 & 121 & 1.4 \\
\hline P4 154A-1 & 126.7 & 8.3 & 10.3 & 244.6 & 47.6 & 26.5 & 86 & 113 & 1.3 \\
\hline P1 264-1 & 112 & 15.3 & 17.7 & 164.1 & 43.1 & 26.5 & 95 & 129 & 1.3 \\
\hline P1 269-1 & 123.7 & 11 & 12.7 & 152.2 & 51.6 & 27 & 93 & 121 & 1.3 \\
\hline P4 109-1 & 135.2 & 10.8 & 25.8 & 152 & 60.1 & 26.7 & 81 & 112 & 1.3 \\
\hline P5 206-1 & 143.2 & 11.2 & 29 & 172.8 & 57.3 & 29.8 & 84 & 119 & 1.3 \\
\hline P1 72-1 & 119 & 17.7 & 24 & 202.6 & 56.4 & 28.8 & 94 & 126 & 1.2 \\
\hline P4 350-1 & 111.6 & 7.6 & 8.4 & 230.6 & 63.5 & 26.2 & 79 & 111 & 1.2 \\
\hline P1 233-1 & 115.2 & 12.2 & 21 & 181.1 & 81.8 & 28.7 & 93 & 126 & 1.2 \\
\hline P4 428-1 & 130.5 & 11.8 & 22.5 & 139 & 70.2 & 24.3 & 75 & 117 & 1.2 \\
\hline P4 117A-1 & 135.8 & 8.2 & 15.2 & 190 & 60.5 & 26.1 & 86 & 111 & 1.1 \\
\hline P1 2-1 & 116.8 & 20 & 25.5 & 128.4 & 72.5 & 22.5 & 92 & 129 & 1.1 \\
\hline P1 45-1 & 109.3 & 14 & 32.3 & 146.5 & 86.7 & 26.3 & 92 & 119 & 1.1 \\
\hline P4 123-1 & 130 & 14.3 & 21 & 181.4 & 68.1 & 28.3 & 88 & 126 & 1.1 \\
\hline P4 475-1 & 73.7 & 10 & 23 & 163.3 & 37.2 & 24.7 & 81 & 112 & 1.1 \\
\hline P2 220-1 & 141.8 & 14.2 & 16.8 & 145.5 & 47.8 & 23.6 & 88 & 126 & 1.1 \\
\hline P5 384-1 & 166.2 & 10.4 & 17.2 & 178.7 & 98.4 & 30 & 89 & 119 & 1.1 \\
\hline P1 235-1 & 128.3 & 14.7 & 36.7 & 186.4 & 78.8 & 28.2 & 93 & 119 & 1 \\
\hline P3 93-1 & 130 & 10 & 22 & 150 & 98.9 & 25.7 & 81 & 109 & 1 \\
\hline P1 453-1 & 96.3 & 10.7 & 17.3 & 120.1 & 47.2 & 27.2 & 95 & 133 & 0.9 \\
\hline P4 417A-1 & 110.8 & 9 & 19.4 & 129.5 & 31.2 & 21.9 & 81 & 112 & 0.9 \\
\hline P2 83B-1 & 151.8 & 10.6 & 23.4 & 214.6 & 74.2 & 30.4 & 84 & 113 & 0.9 \\
\hline
\end{tabular}


Deswina dkk, SELEKSI VARIETAS PADI...

\begin{tabular}{lccccccccc} 
P5 370-1 & 149.7 & 15.3 & 15.3 & 122.5 & 90.9 & 28 & 88 & 118 & 0.9 \\
P1 443-1 & 104.3 & 15 & 24 & 124 & 56.3 & 26.5 & 93 & 129 & 0.8 \\
P1 465-1 & 117.4 & 9.4 & 12.4 & 138.2 & 42.6 & 28.3 & 95 & 133 & 0.8 \\
P3 89-1 & 116 & 8.7 & 18 & 159.8 & 99.7 & 25.4 & 78 & 109 & 0.7 \\
P1 75-1 & 113.3 & 8.7 & 13 & 159.3 & 78 & 26.4 & 95 & 129 & 0.6 \\
P3 182-1 & 108.7 & 9.3 & 20.3 & 95.7 & 52.1 & 24 & 81 & 119 & 0.6 \\
P4 117B-1 & 109.2 & 14.2 & 35.6 & 103.8 & $\mathbf{1 9 . 6}$ & 26.5 & $\mathbf{7 4}$ & 98 & 0.6 \\
P3 310-1 & 98.7 & $\mathbf{6 . 7}$ & 24.7 & 122.6 & 96.2 & 23.6 & 102 & 109 & 0.6 \\
P4 337-1 & 111.7 & 13.3 & 32.7 & 155.2 & 83.6 & 26.2 & 102 & 130 & 0.6 \\
P5 367-1 & 149.7 & 11 & 12 & 124.4 & 97.6 & 27.9 & 88 & 118 & 0.6 \\
P4 356-1 & 96.8 & 9 & 17 & 131.8 & 64.9 & 22.1 & 75 & 109 & 0.5 \\
P1 275-1 & 122.7 & 12.7 & 19.3 & 144.9 & 98.6 & 25.1 & 86 & 126 & 0.4 \\
P3 103-1 & 138.7 & 11 & 13 & 241 & 99.6 & 29.6 & 81 & 106 & 0.4 \\
P1 248-1 & 121.3 & 16 & 24.3 & 146 & 40.6 & 27.3 & 94 & 133 & 0.3 \\
P1 468-1 & 106.5 & $\mathbf{7}$ & 11.3 & 136.2 & 87.6 & 27.4 & 93 & 140 & 0.2 \\
\hline Ker
\end{tabular}

Keterangan: TT = tinggi tanaman, JAP = jumlah anakan produktif, JAT = jumlah anakan total, GH= gabah hampa, GT= gabah total, $\mathrm{PM}=$ panjang malai, $\mathrm{UB}=$ umur berbunga, $\mathrm{UP}=$ umur tanaman, $\mathrm{P}=$ produksi

Tabel 4. Karakter agronomik pada varietas cek yang digunakan dalam UDHP

\begin{tabular}{cccccccccc}
\hline Genotipe & TT $(\mathrm{cm})$ & JAP & JAT & GT & $\begin{array}{l}\text { GH } \\
(\%)\end{array}$ & PM $(\mathrm{cm})$ & UB & UP & $\begin{array}{c}\text { P } \\
\text { (ton/ } \\
\text { ha) }\end{array}$ \\
\hline Situ Patenggang & 105.4 & 9.8 & 20.0 & 142.9 & 56.0 & 24.8 & 82.0 & 112.3 & 1.4 \\
Limboto & 129.2 & 9.3 & 13.8 & 176 & 35.6 & 26.1 & 85.7 & 124.0 & 1.7 \\
LIPI Go2 & 132.1 & 17.0 & 26.3 & 107.8 & 70.8 & 22.7 & 86.3 & 113.7 & 0.8 \\
Danau Gaung & 129.8 & 10.7 & 16.0 & 150.8 & 71.1 & 28.5 & 88.0 & 127.0 & 1.4 \\
IR 64 & $\mathbf{9 4 . 5}$ & $\mathbf{2 1 . 8}$ & $\mathbf{3 3 . 5}$ & 130.5 & 53.7 & 25.3 & $\mathbf{9 0 . 7}$ & 120.3 & $\mathbf{2 . 7}$ \\
\hline
\end{tabular}

Berdasarkan penelitian Deswina et al (2016) terhadap 60 tanaman padi gogo hasil persilangan, $52 \%$ petani lebih menyukai tinggi tanaman sedang dengan tinggi antara 90-125 $\mathrm{cm}$, sedangkan genotype padi yang paling diminati oleh 14 orang responden adalah P3 402. Selanjutnya 10 orang responden menyukai genotype P1 233 dan P5 39. Berdasarkan hasil pengamatan di lapangan terhadap pertumbuhan padi gogo hasil persilangan, memiliki bentuk pertumbuhan yang beragam, baik dari tinggi tanaman, jumlah anakan jumlah malai dan produktivitas tanaman. Hasil penilaian oleh petani belum dapat dijadikan acuan untuk menentukan jenis yang baik dan sesuai dengan kriteria tanaman unggul. Menurut Witcombe et al (2005) kegiatan PPB tidak umum untuk persilangan konvensional, demikian juga pada penilaian kualitas pasca panen tanaman dan penerimaan pasar terhadap jenis atau varietas tanaman padi. Peran petani lebih besar pada persyaratan pelepasan varietas dan keputusan akhir dari penerimaan dan penolakan terhadap jenis galur baru hasil persilangan. Factor-faktor 
lain yang ikut mempengaruhi keragaman tanaman di lapangan adalah: factor lingkungan seperti iklim dan kondisi tanah yang tidak sesuai dengan pertumbuhan padi gogo, juga jumlah populasi tanaman harus memadai untuk dilakukan penilaian secara langsung. Perlu dilakukan penanaman dengan jumlah populasi yang lebih banyak, agar proses seleksi dan penilaian oleh petani lebih efektif. Metode seleksi merupakan proses yang efektif untuk memperoleh sifat-sifat yang dianggap sangat penting dengan tingkat keberhasilan yang tinggi (Helyanto et al. 2000).

\section{KESIMPULAN}

Dari hasil penelitian dan kegiatan PBB yang telah dilakukan terhadap responden petani, dapat diambil beberapa kesimpulan sebagai berikut:

1. Genotype P4 117B-1 menghasilkan gabah hampa $19.6 \%$, genotype-genotype yang lainnya menghasilkan gabah hampa antara $31.2 \%$ hingga $98.4 \%$.

2. Produktivitas tertinggi dihasilkan dari genotype P1 223 sebesar 3.1 ton/ha, sedangkan varietas pembanding diperoleh dari galur IR64 sebesar 2.7 ton/ha

3. Umur panen untuk semua genotype yang diuji berkisar antara 98 hss - 140 hss, sedangkan pada varietas pembanding berkisar antara 105 hss - 120 hss.

4. Karakter tinggi tanaman pada galur-galur hasil persilangan memiliki kisaran dari
73,7 cm (P4 475-1) - 166,2 cm (P5 384-1), untuk varietas pembanding memiliki kisaran antara $94.5 \mathrm{~cm}$ (IR64) $132.1 \mathrm{~cm}$ (LIPI Go2).

5. Panjang malai tidak menentukan jumlah produksi yang dihasilkan baik pada genotype yang diuji maupun varietasvarietas pembanding.

\section{DAFTAR PUSTAKA}

BPS. 2011. Badan Pusat Statistik Indonesia. Jakarta.

BPS. 2015. BPS. 2015. Jawa Barat Dalam Angka. Badan Pusat Statistik Jawa Barat.

Brockett P., Levine P. 1984. Statistics and probability and their applications. Saunders College Publishing. Philadelphia.

[FAO]. 2009. FAOSTAT. database [online] :http://faostat.fao.org.

Bakhtiar, Hasanuddin., T. Hidayat. 2013. Identifikasi Beberapa Varietas Unggul Padi Gogo di Aceh Besar. Jurnal Agrista:17 (2): 49-54.

Balitbang. 2001. Kementerian Pertanian. Indonesia.

Deswina P., E.B. Mei Adi, E.S Mulyaningsih. 2016. Participatory Plant Breeding (PPB) dalam Meningkatkan Kualitas Tanaman Padi Hasil Persilangan di Indonesia. Prosiding Seminar Nasional.Lembaga Penelitian dan Pengabdian Kepada Masyarakat. Universitas Jenderal Soedirman. Purwokerto 24-25 November 2016 : 121-134.

Handoko, I.,Y. Sugiarto, Y.Syaukat. 2008. Keterkaitan perubahan iklim dan produksi pangan strategis: Telaah kebijakan independen dalam bidang perdagangan dan pembangunan, SEAMEO BIOTROP for Kemitraan Partnership.

Helyanto, B., U.S. Budi, A. Kartamidjaya, D. Sunardi. 2000. Studi parameter genetik hasil serat dan komponennya pada plasma 
nutfah rosela. Jurnal Pertanian Tropika 8(1):82-87.

Kartina N., B.P Wibowo, Y. Widyastuti, I.A. Rumanti, Satoto. 2016. Korelasi dan Sidik Lintas Karakter Agronomi Padi Hibrida. J Ilmu Pertanian Indonesia (JIPI). Vol. 21

(2): 76-83

Kementerian Pertanian. 2013. Konsep strategi induk pembangunan pertanian 2013-2045. Pertanian-Bioindustri Berkelanjutan. Solusi pembangunan Indonesia masa depan. Biro Perencanaan Sekretariat Jenderal Kementerian Pertanian. Hal. 2847.

Khush, G.S., 2000. Strategies for increasing the yield potential of rice, in Sheehy J. E. (ed) Redesigning rice photosynthesis to increase yield. International Rice Research Institute. Los Banos, Philippines. P. 207212.

Makarim,A.K., E. Suhartatik. 2009. Morfologi Dan Fisiologi Tanaman Padi. Balai Besar Penelitian Padi. Departemen Pertanian.

Qi-hua L., L. Xiu, C. Bo-cong, M. Jia-qing, G. Jie. 2014. Effects of Low Light on Agronomic and Physiological Characteristics of Rice Including Grain Yield and Quality. Rice Science, 21(5): 243-251.

Seno, D.S.H., A.E.Z. Hasan, B. Kusbiantoro., T.J. Santoso dan Z. A. Mas'ud. 2011. Identifikasi Gen Aroma Pada ProgeniProgeni Backcross Antara Varietas Ciherang Dengan Pandan Wangi. Jurnal llmu Pertanian Indonesia, Agustus 2011. Hal:136-141. ISSN 0853-4217.

Sadimantara, GR., A. Widarsih., Muhidin. 2013. Seleksi Beberapa Progeni Hasil Persilangan Padi Gogo (Oryza sativa L.)
Berdasarkan Karakter Pertumbuhan Tanaman. Jurnal Agroteknos. 3 (1): 48-52. ISSN 2087-7706.

Sembiring H. 2015. Pedoman teknis GP-PTT padi. Direktorat Jenderal Tanaman Pangan. Kementerian Pertanian. Jakarta.

Shivani, D.K., Dwivedi, R. Husain, K. Gyanendra, G. Yadav, G. Kumar, Sanghmitra, O.N. Singh, N. Vikram and N.A. Khan. 2017. Physiological, Morphological and Molecular Mechanisms for Drought Tolerance in Rice. Int.J.Curr.Microbiol.App.Sci. 6(7): 4160-4173.

Susilaningsih F., D. Ruswandi dan N. Hermiati. 2008. Penampilan Fenotipik dan Beberapa Parameter Genetik 16 Kultivar Padi Gogo pada Sistem Tumpangsari 3:1 dengan Kacang Tanah di Jatinangor. Zuriat. 19: 153-163.

Witcombe, J.R., K.D. Joshi, S. Gyawali, A.M. Musa, C. Johansen, D.S. Virk, and B.R. Sthapit. 2005. Participat ory plant breeding is better described as highly client-oriented plant breeding. I. Four indicators of client-orientation in plant breeding. Expl. Agric. 41:299-319.

Virk, D.S., D.N. Singh, S.C. Prasad, J.S. Gangwar and J.R. Witcombe. 2003. Collaborative and consultative participatory plant breeding of rice for the rainfed uplands of eastern India. Euphytica 132:95-108.

Zuraida, N dan Sumarno. 2003. Partisipasi petani dalam pemuliaan tanaman dan konservasi plasma nutfah secara 'on farm'. Jurnal Zuriat Vol. 14 (2): Puslitbang Tanaman Pangan, Bogor. 